\title{
On the Robustness of the Weakening Effect of Anthropogenic Aerosols on the East Asian Summer Monsoon with Multimodel Results
}

\author{
Hongli Wang, ${ }^{1}$ Xiaoning Xie, ${ }^{1}$ and Xiaodong Liu ${ }^{1,2}$ \\ ${ }^{1}$ SKLLQG, Institute of Earth Environment, Chinese Academy of Sciences, Xian 710075, China \\ ${ }^{2}$ Department of Environmental Science and Technology, School of Human Settlements and Civil Engineering, \\ Xian Jiaotong University, Xian 710049, China \\ Correspondence should be addressed to Xiaoning Xie; xnxie@ieecas.cn
}

Received 3 July 2014; Accepted 30 December 2014

Academic Editor: Francisco J. Tapiador

Copyright ( 2015 Hongli Wang et al. This is an open access article distributed under the Creative Commons Attribution License, which permits unrestricted use, distribution, and reproduction in any medium, provided the original work is properly cited.

Using outputs from 10 CMIP5 models with fixed sea surface temperature, we investigate the fast response of the East Asian summer monsoon (EASM) and summer precipitation in East China to anthropogenic aerosols. To address this topic, we employ two commonly used EASM indices that can represent zonal and meridional land-sea thermal contrast, respectively. The results reveal that the notion of a weakened EASM in response to increased anthropogenic aerosols is a robust one, as well as decreased precipitation in East China. The ensemble mean of decreased precipitation in the aerosol run was about $6.6 \%$ in comparison to the CTL run and could be enlarged to $8.3 \%$ by excluding the experiments with the aerosol direct effect only. Convective precipitation was found to be the primary contributor $(>80 \%)$ to the reduction of total precipitation. The combination of direct and indirect effects of aerosols can decrease solar radiation reaching the Earth's surface and eventually modulate large-scale EASM circulation and suppress summer precipitation in East China. The uncertainties and discrepancies among the models highlight the complexity of interaction in aerosol-precipitation processes when investigating present and future changes of the EASM.

\section{Introduction}

The East Asian summer monsoon (EASM) has tremendous impacts on socioeconomic development throughout East Asia [1]. The intensity of the EASM has undergone a weakening trend since the late 1970s, and there have been many efforts made to predict its variation and the underlying mechanisms involved [2]. Previous studies indicate that the EASM is affected by numerous factors, including the sea surface temperature (SST) over the Indian and Pacific Ocean and the snow cover on the Tibetan Plateau [3], land use change [4], and increased concentrations of greenhouse gases and atmospheric aerosols [5]. With an increasing aerosol loading in East Asia during recent years, the climatic effects of atmospheric aerosols over this region have received considerable research interest [6].

It is generally recognized that aerosols affect climate change through a reduction of solar radiation (direct effect) and interactions with cloud microphysical processes (indirect effect) [6]. Aerosol effects are likely to cause inhomogeneous land-sea heating and pressure gradients and induce changes in large-scale atmospheric circulation and precipitation in East Asia. However, the aerosol indirect effect is still considered to be an uncertain factor in anthropogenic forcing, and uncertainties relating to aerosol-induced radiative forcing remain large due to the complexity of aerosol-cloud interaction $[7,8]$. In addition, aerosol effects on precipitation processes are even more uncertain; much of the interaction that takes place between aerosols and precipitation is not well understood $[6,9]$.

Numerical models with improved skill provide advances in detecting the climatological features induced by anthropogenic aerosols. The climate response to aerosol forcing is more localized over land [10], and many researchers have investigated the effects of anthropogenic aerosols on East Asian climate variability. Based on the NCAR Community 
TABLE 1: List of the CMIP5 models used in this study.

\begin{tabular}{|c|c|c|c|c|}
\hline Model name & Atmospheric component & $\begin{array}{c}\text { Resolution } \\
(\text { Lat } \times \text { Lon, Lev })\end{array}$ & $\begin{array}{l}\text { Aerosol } \\
\text { (effects) }\end{array}$ & Country/center \\
\hline BCC-CSM1.1 & BCC-AGCM2.1 & $64 \times 128$, L17 & $\begin{array}{l}\text { Prescribed } \\
\text { (DE) }\end{array}$ & China/BCC \\
\hline CanESM2 & CanAM4 & $64 \times 128, \mathrm{~L} 17$ & $\begin{array}{l}\text { Prescribed } \\
(\mathrm{DE}+\mathrm{IDE})\end{array}$ & Canada/CCCMA \\
\hline CSIRO-Mk3.6.0 & $\begin{array}{c}\text { Mk3.6 atmosphere } \\
\text { component }\end{array}$ & $96 \times 192$, L18 & $\begin{array}{c}\text { Online } \\
(\mathrm{DE}+\mathrm{IDE})\end{array}$ & Australia/CSIRO \\
\hline FGOALS-s2 & SAMIL2 & $108 \times 128, \mathrm{~L} 17$ & $\begin{array}{l}\text { Prescribed } \\
\text { (DE) }\end{array}$ & China/LASG-IAP \\
\hline GFDL-CM3 & AM3p9 & $90 \times 144, \mathrm{~L} 23$ & $\begin{array}{l}\text { Prescribed } \\
(\mathrm{DE}+\mathrm{IDE})\end{array}$ & USA/NOAA \\
\hline HadGEM2-A & HadGAM2 & $144 \times 192$, L17 & $\begin{array}{c}\text { Online } \\
\text { (DE + IDE) }\end{array}$ & UK/MOHC \\
\hline IPSL-CM5A-LR & LMDZ4 v5 & $96 \times 96$, L17 & $\begin{array}{c}\text { Online } \\
\text { (DE + IDE) }\end{array}$ & France/IPSL \\
\hline MIROC5 & $\begin{array}{c}\text { CCSR/NIES/FRCGC } \\
\text { AGCM }\end{array}$ & $128 \times 256, \mathrm{~L} 17$ & $\begin{array}{c}\text { Online } \\
\text { (DE + IDE) }\end{array}$ & Japan/MIROC \\
\hline MRI-CGCM3 & GSMUV & $160 \times 320, \mathrm{~L} 23$ & $\begin{array}{c}\text { Online } \\
(\mathrm{DE}+\mathrm{IDE})\end{array}$ & Japan/MRI \\
\hline NorESM1-M & CAM4-Oslo & $96 \times 144, \mathrm{~L} 17$ & $\begin{array}{c}\text { Online } \\
\text { (DE + IDE) }\end{array}$ & Norwegian/NCC \\
\hline
\end{tabular}

DE, direct effect; IDE, indirect effect.

Atmosphere Model, Liu et al. [11] reported a prominent decline in rainfall over East China due to the effect of all anthropogenic aerosols, and similar results were also revealed by Jiang et al. [12]. Song et al. [13] pointed out that anthropogenic aerosols cannot be ignored when considering the weakening of the EASM with ocean-atmosphere coupled models. It is known that the climate response to anthropogenic aerosols involves both slow and fast processes [14]; adjustments of the ocean to aerosols (slow response) take place on time scales that are much longer than those involved in the impact of aerosols on radiation (fast response) [8]. To the best of our knowledge, previous studies have mostly been based on a single model, and the fast response of the EASM to anthropogenic aerosols using a multimodel approach remains poorly investigated.

In contrast to previous studies, we focus on the fast response of the EASM and summer precipitation over East China to anthropogenic aerosols. The main purpose of this study is to verify whether the weakening effect of anthropogenic aerosols on the EASM is a robust feature. The remainder of the paper is organized as follows. The model simulations and methodologies used in this study are introduced in Section 2. The fast response of the anthropogenic aerosols effect on the EASM is revealed using simulation results from the Coupled Model Intercomparison Program phase 5 (CMIP5) models in Section 3. A summary and discussion of the key findings are provided in Section 4.

\section{Data and Methodology}

2.1. Model Description. We use the simulation results from 10 models that participated in CMIP5. There are two sets of fixed
SST experiments for each model: one is designed with natural aerosols only at the 1850AD level (control run; hereafter CTL run) and the other with both anthropogenic and natural aerosols at the 2000AD level (hereafter aerosol run). The climate variations response to the effect of anthropogenic aerosols is illuminated by the difference between the aerosol run and CTL run (the aerosol run minus the CTL run). In order to extract the effect of anthropogenic aerosols, other boundary conditions and forcing agents (greenhouse gas concentrations, solar radiative forcing, and SST) are fixed at $1850 \mathrm{AD}$ levels in both experiments. Among these simulations, eight models run with the direct and indirect effects of aerosols together, while the other two models (BCC-CSM1.1 and FGOALS-s2) only take the aerosol direct effect into account. Six models simulate aerosol chemistry and physics online, while the other four models utilize prescribed aerosol fields. The model simulations use horizontal resolutions of $64 \times 128$ to $160 \times 320$, with vertical layers varying from 17 to 23 levels in the atmosphere. Each of these models is run for 30-60 years, and 30 years of simulations are used in our analysis. Although these models are developed as atmosphere-ocean coupled models, as the SST is fixed in the simulations, they can be considered as atmospheric models here. As we focus our assessment on the fast response of the EASM to anthropogenic aerosols, these simulations, excluding the impacts of aerosol-SST interactions, provide us with the means to explore this issue. Detailed information on the atmospheric components, resolutions, aerosol schemes, and the modeling centers responsible for the development of the models is provided in Table 1.

All the model simulations are interpolated onto a $2.5^{\circ} \times$ $2.5^{\circ}$ grid via bilinear interpolation. The ensemble result is 
TABLE 2: The EASMI calculated by the Guo and Han indices in the CTL and aerosol runs.

\begin{tabular}{lcccc}
\hline Model & Guo index (CTL run) & Guo index (aerosol run) & Han index (CTL run) & Han index (aerosol run) \\
\hline BCC-CSM1.1 & -31.41 & -30.93 & -4.82 & -5.03 \\
CanESM2 & -48.66 & $-46.92^{*}$ & -7.99 & $-8.76^{* *}$ \\
CSIRO-Mk3.6.0 & -55.31 & $-53.48^{*}$ & -9.13 & -9.31 \\
FGOALS-s2 & -39.86 & -39.29 & -4.44 & -5.10 \\
GFDL-CM3 & Null & -28.84 & -9.40 & $-10.89^{* *}$ \\
HadGEM2-A & -47.21 & $-46.66^{*}$ & -3.47 & $-4.76^{* *}$ \\
IPSL-CM5A-LR & -31.07 & -30.80 & -13.50 & -13.40 \\
MIROC5 & -54.13 & $-49.09^{* *}$ & -5.40 & $-7.31^{* *}$ \\
MRI-CGCM3 & -21.10 & -20.68 & -13.98 & $-14.48^{*}$ \\
NorESM1-M & -44.02 & -42.74 & -5.62 & $-6.98^{* *}$ \\
Ensemble results & -41.00 & $-39.47^{* *}$ & -7.10 & $-7.79^{* *}$ \\
\hline
\end{tabular}

*Significant at the 0.10 level; ${ }^{* *}$ significant at the 0.01 level; "Null" indicates that the SLP data in the GFDL-CM3 CTL run are missing.

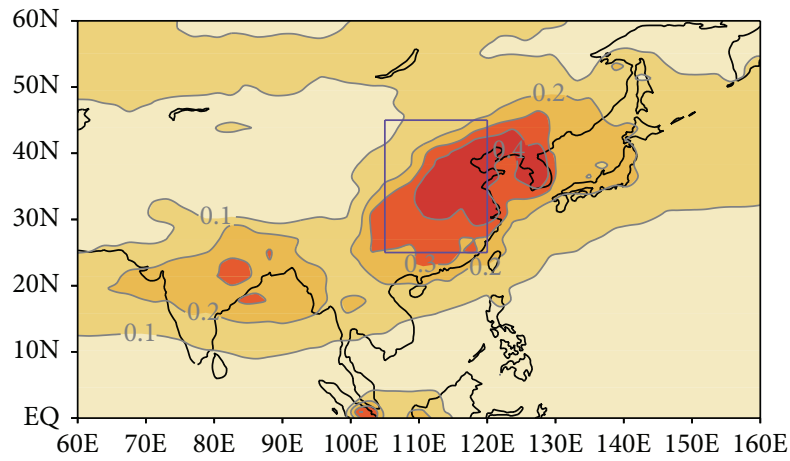

FIgURE 1: Spatial distribution of the $550 \mathrm{~nm}$ aerosol optical depth difference between two experiments for summer (JJA) derived from the CSIRO-Mk3.6.0 model. The purple box represents the study region (East China; $25^{\circ}-45^{\circ} \mathrm{N}, 105^{\circ}-120^{\circ} \mathrm{E}$ ).

achieved by averaging the 10 simulations with equivalent weight. To assess the overall performance of the climate models in simulating summer climatology, we examine the mean sea level pressure (SLP), $200 \mathrm{hPa}$ zonal wind, and $850 \mathrm{hPa}$ winds between the CTL run from the multimodel ensemble and ECMWF 40-year reanalysis data (ERA40) [15] (see Figure S1 in Supplementary Material available online at http://dx.doi.org/10.1155/2015/397395) and calculate the spatial correlation coefficients of the mentioned circulation fields between the outputs from CTL run of the 10 models and ERA40 (Table S1). It is found that the models can reproduce reasonably well the land-sea difference of SLP, the distributions of zonal winds at $200 \mathrm{hPa}$, and the southerly winds that bring moisture from the oceans at the $850 \mathrm{hPa}$ level. The results suggest that the circulation climatology of East Asia in the CTL run is comparable to ERA40.

2.2. Study Region. Due to rapid industrialization in recent decades, East Asia has become one of the dominant emission sources of anthropogenic aerosols in the world. Figure 1 shows the climatological distribution of aerosol optical depth (AOD) difference between two experiments for summer, and all the models with online aerosols show a similar distribution of AOD in East Asia (figures are omitted). Our study region is located in East China, which is an area with large AOD. Our aim is to identify the circulation pattern of the EASM and the concomitant precipitation change over the study region in response to anthropogenic aerosols.

2.3. Choice of East Asian Summer Monsoon Index (EASMI). Since the EASM encompasses the tropics, subtropics, and midlatitudes, it is difficult to measure its strength due to its complex spatiotemporal structures [16]. Based on the notion that the EASM may be determined by the land-ocean thermal contrast, we use two monsoon indices defined by Guo [17] and by Han and Wang [18] (hereafter Guo index and Han index, resp.). The Guo index is constructed by the summation of summer SLP difference in the area $\left(10^{\circ}-50^{\circ} \mathrm{N}\right.$, $\left.110^{\circ}-160^{\circ} \mathrm{E}\right)$ and represents the east-west thermal contrast. The Han index is defined by vertical shear of zonal winds between $850 \mathrm{hPa}$ and $200 \mathrm{hPa}$ averaged over $\left(20^{\circ}-40^{\circ} \mathrm{N}, 110^{\circ}-\right.$ $140^{\circ} \mathrm{E}$ ) and emphasizes the importance of the north-south thermal contrast [19].

\section{Results}

3.1. The Weakened EASM Effect of Anthropogenic Aerosols. We calculate the EASMI with simulations from 10 models using the Guo and Han indices. The monsoon indices derived from all the models shown in Table 2 are the climatological mean and without standardization. The intensity of EASM variation affected by anthropogenic aerosols is estimated by the original value. By definition, a smaller (larger) negative value of the Guo index (Han index) means a smaller difference of zonal (meridional) thermal contrast and reflects a weaker EASM. From Table 2, a weakened variation in the EASM with increasing anthropogenic aerosols is apparent in almost all the models, except IPSL-CM5A-LR. Furthermore, in order to test the significance of the difference between the two simulations, Student's $t$-test is employed. The results show that the weakened variations of the ensemble mean due to the effect of anthropogenic aerosols are statistically significant at the $P<0.01$ level. It is interesting to note that most models reflecting the weakened variation show 


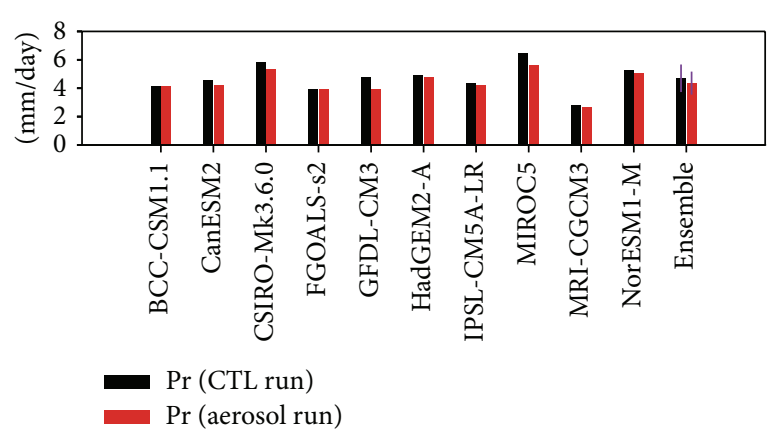

(a)

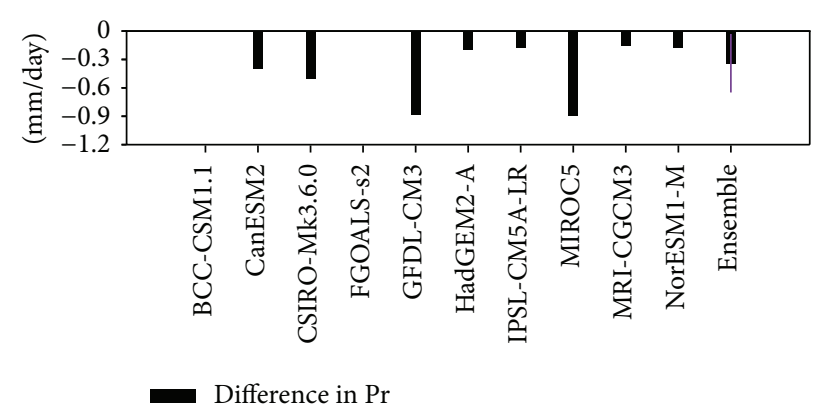

(b)

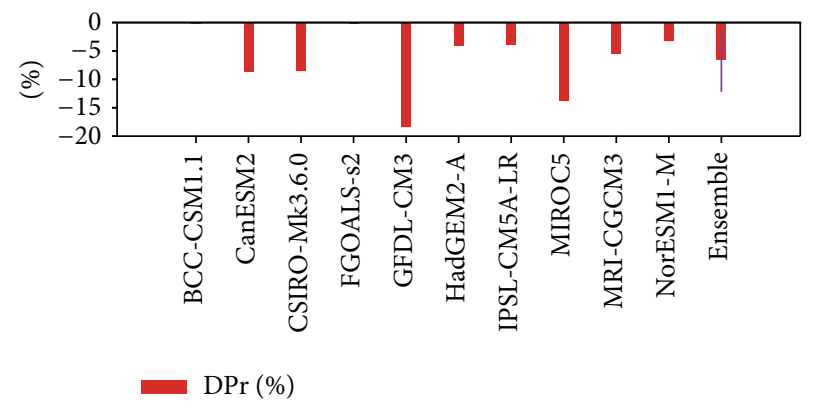

(c)

Figure 2: (a) Summer precipitation of the aerosol run (red bars) and CTL run (black bars) for each model over East China. (b) Same as (a), except for the precipitation difference between the aerosol run and CTL run (aerosol minus CTL). (c) Ratio of precipitation differences in (b) to the CTL run in each model. The far right bar and purple line in each panel are the ensemble mean and standard deviation from all simulations, respectively.

significance at the $P<0.10$ level, based on the experiments with direct and indirect effects (except IPSL-CM5A-LR), while neither of the two indices in the experiments with the direct effect only pass the significance test, implying that the indirect effect may play a more important role in the EASM's circulation. Among the experiments with both direct and indirect aerosol effects, the significant tests of the EASMI do not show any clear distinction between the experiments with prescribed and online aerosol schemes. Therefore, from the east-west and north-south thermal contrast viewpoints, a weakened EASM as a result of anthropogenic aerosols is an apparent feature.

3.2. Variation of Summer Precipitation over East China. Precipitation is one of the main regimes of the monsoon climate. The summer precipitation in East China is largely contributed to the intensity of the EASM [1]. From the regional average summer precipitation, we find that the precipitation from the aerosol run is decreased in comparison to the CTL run in all the models. The range of the decreased precipitation is from 0.01 to $0.89 \mathrm{~mm} /$ day, and the ensemble mean indicates that the reduction is circa $0.34 \mathrm{~mm} /$ day and $6.6 \%$ compared to the CTL run (Figure 2). It is noted that the precipitation decreased slightly in the experiments with the aerosol direct effect only, being about $0.01 \mathrm{~mm} /$ day for BCC-CSM1.1 and FGOALS-s2. This result may imply the importance of the aerosol indirect effect. The precipitation can be decreased by $8.3 \%$ in the experiments without BCC-CSM1.1 and FGOALSs2. Additionally, there also exists much uncertainty and discrepancy in the aerosol-induced precipitation change among the eight models with aerosol direct and indirect effects, likely due to the complex interaction of aerosol-precipitation processes [20].

The precipitation can be divided into convective precipitation and large-scale precipitation by the producing mechanisms in the model simulation. The range of convective precipitation reduction is from 0.016 to $0.73 \mathrm{~mm} /$ day in the aerosol run in comparison to the CTL run, and the decrease in large-scale precipitation is relatively less (Table 3). By contrast, a striking proportion of the decrease $(82.4 \%)$ is attributed to changes in convective precipitation on average, while just $17.6 \%$ of the decrease is ascribed to variations in large-scale precipitation. Convective precipitation and largescale precipitation are repressed in the experiments with both the aerosol direct and indirect effects, while the experiments with direct effects only show an increase in large-scale precipitation. In short, more than $80 \%$ of the decrease of precipitation is mainly due to convective precipitation.

3.3. Change of Large-Scale Circulation. Based on the above analysis, we know that the EASM can be weakened by the effect of anthropogenic aerosols and induced precipitation decrease in East China. The EASM is a subtropical monsoon; the low-level winds reverse primarily from southerlies [21]. But how do the models represent the relevant circulation difference? Figure 3 shows the multimodel ensemble mean of the circulation difference. It is clear that increasing anthropogenic aerosols results in a decreasing of the continental 
TABLE 3: Convective precipitation (PRCC) and large-scale precipitation (PRCL) difference between the aerosol run and CTL run and the ratio of the difference to the total precipitation decrease.

\begin{tabular}{|c|c|c|c|c|c|}
\hline \multirow{2}{*}{ Model name } & \multirow{2}{*}{ Total decrease (mm/day) } & \multicolumn{2}{|c|}{ PRCC } & \multicolumn{2}{|c|}{ PRCL } \\
\hline & & Decrease (mm/day) & Percentage (\%) & Decrease (mm/day) & Percentage (\%) \\
\hline BCC-CSM1.1 & -0.01 & -0.016 & 153.3 & 0.006 & -53.3 \\
\hline CanESM2 & -0.4 & -0.24 & 58.8 & -0.16 & 41.2 \\
\hline CSIRO-Mk3.6.0 & -0.5 & -0.47 & 94.0 & -0.03 & 6.0 \\
\hline FGOALS-s2 & -0.01 & -0.03 & 300.0 & 0.02 & -200.0 \\
\hline GFDL-CM3 & -0.88 & -0.72 & 81.8 & -0.16 & 18.2 \\
\hline HadGEM2-A & -0.2 & -0.12 & 57.9 & -0.08 & 42.1 \\
\hline IPSL-CM5A-LR & -0.17 & -0.27 & 160.1 & 0.10 & -60.1 \\
\hline MIROC5 & -0.89 & -0.73 & 82.5 & -0.16 & 17.5 \\
\hline MRI-CGCM3 & -0.15 & -0.08 & 55.1 & -0.07 & 44.9 \\
\hline NorESM1-M & -0.17 & -0.15 & 88.2 & -0.02 & 11.8 \\
\hline Ensemble & -0.34 & -0.28 & 82.4 & -0.06 & 17.6 \\
\hline
\end{tabular}

TABLE 4: Comparisons between the aerosol run and the CTL run in East China in terms of specific humidity, moisture flux, and convergence/divergence at $850 \mathrm{hPa}$.

\begin{tabular}{lccccccccc}
\hline \multirow{2}{*}{ Model name } & \multicolumn{3}{c}{ Specific humidity $(\mathrm{g} / \mathrm{kg})$} & \multicolumn{3}{c}{ Water vapor flux $(\mathrm{g} /(\mathrm{hPa} \cdot \mathrm{m} \cdot \mathrm{s}))$} & \multicolumn{3}{c}{ Convergence/divergence $\left(10^{-5} \mathrm{~g} /\left(\mathrm{hPa} \cdot \mathrm{m}^{2} \cdot \mathrm{s}\right)\right)$} \\
& CTL & Aerosol & Aerosol-CTL & CTL & Aerosol & Aerosol-CTL & CTL & Aerosol & Aerosol-CTL \\
\hline BCC-CSM1.1 & 9.33 & 9.37 & 0.04 & 32.63 & 31.58 & -1.05 & -0.75 & -0.69 & 0.06 \\
CanESM2 & 11.79 & 11.54 & -0.24 & 31.69 & 29.13 & -2.56 & -0.66 & -0.56 & 0.10 \\
CSIRO-Mk3.6.0 & 12.30 & 12.16 & -0.14 & 26.50 & 23.74 & -2.76 & -0.21 & -0.07 & 0.14 \\
FGOALS-s2 & 8.60 & 8.70 & 0.10 & 40.70 & 39.09 & -1.61 & -0.77 & -0.81 & -0.04 \\
GFDL-CM3 & 10.05 & 9.66 & -0.38 & 21.78 & 19.10 & -2.68 & -0.03 & 0.18 & 0.21 \\
HadGEM2-A & 10.90 & 10.76 & -0.14 & 23.38 & 20.12 & -3.26 & -0.91 & -0.91 & 0.00 \\
IPSL-CM5A-LR & 9.10 & 9.07 & -0.03 & 15.85 & 15.03 & -0.82 & -0.35 & -0.31 & 0.04 \\
MIROC5 & 11.50 & 11.10 & -0.40 & 37.65 & 33.77 & -3.88 & -1.53 & -1.08 & 0.45 \\
MRI-CGCM3 & 7.25 & 7.33 & 0.08 & 24.19 & 23.92 & -0.27 & 0.28 & 0.33 & 0.05 \\
NorESM1-M & 11.08 & 10.89 & -0.19 & 43.00 & 36.05 & -6.94 & -0.44 & -0.32 & 0.12 \\
Ensemble & 10.19 & 10.06 & -0.13 & 29.74 & 27.15 & -2.59 & -0.54 & -0.42 & 0.12 \\
\hline
\end{tabular}

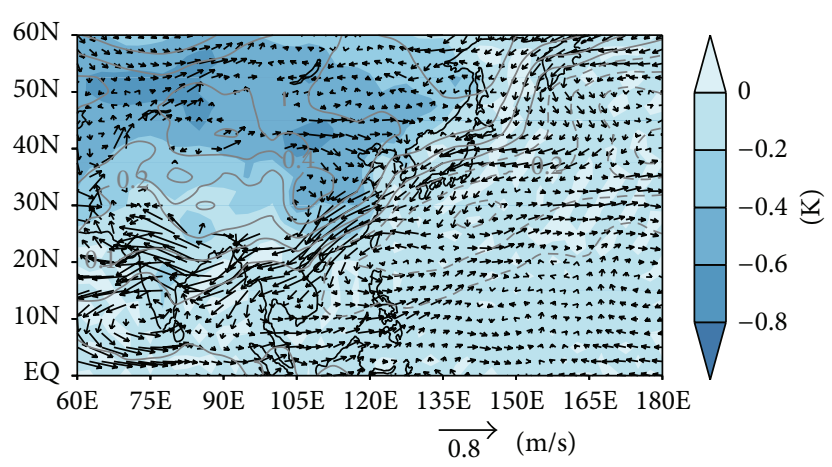

Figure 3: Multimodel climatological mean (30 years) of the difference (aerosol run minus CTL run) of summer surface temperature (shading; units: K), SLP (contours; units: $\mathrm{hPa}$ ), and $850 \mathrm{hPa}$ winds (vectors; units: $\mathrm{m} / \mathrm{s}$ ).

East Asian surface temperature, leading to a reduction of the land-sea thermal contrast and the east-west pressure gradient. The lowered southerly winds are subsequently weakened, thus restraining the passage of water vapor from the ocean. In summary, the decreased precipitation in East China is closely associated with the weakening of the EASM induced by the effect of anthropogenic aerosols. Anthropogenic aerosols weaken the monsoon circulation through reducing the landsea thermal contrast and the horizontal pressure gradient, weakening the southerly winds, and suppressing the flux of water vapor from the ocean into East Asia, thus reducing rainfall in East China. This result confirms the findings of Lau et al. [6].

During summer, East China is dominated by southerly winds at $850 \mathrm{hPa}$, bringing moisture from the ocean. To examine how the decreased precipitation is affected by regional circulation over East China, we calculate regionally averaged values of specific humidity and moisture flux variables at $850 \mathrm{hPa}$ and compare the results between the aerosol run and CTL run (Table 4). The specific humidity is reduced in almost all of the models except BCC-CSM1.1 and FGOALSs2. All the models clearly indicate decreased water vapor transfer to the study region with the anthropogenic aerosols effect. Almost all of the models indicate suppression of 


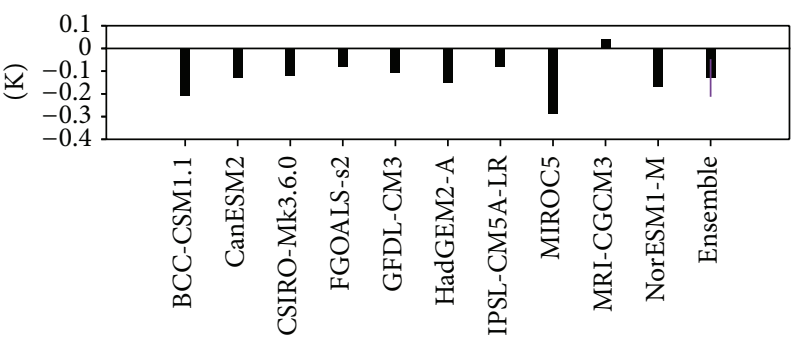

Difference in TS

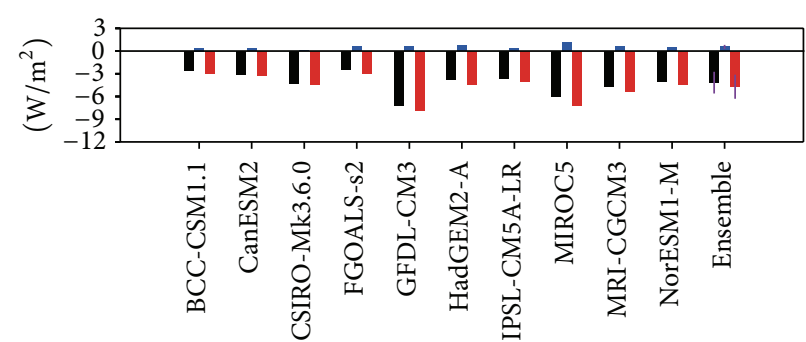

Difference in RTS

Difference in RSS
Difference in RLS

(a)

(b)

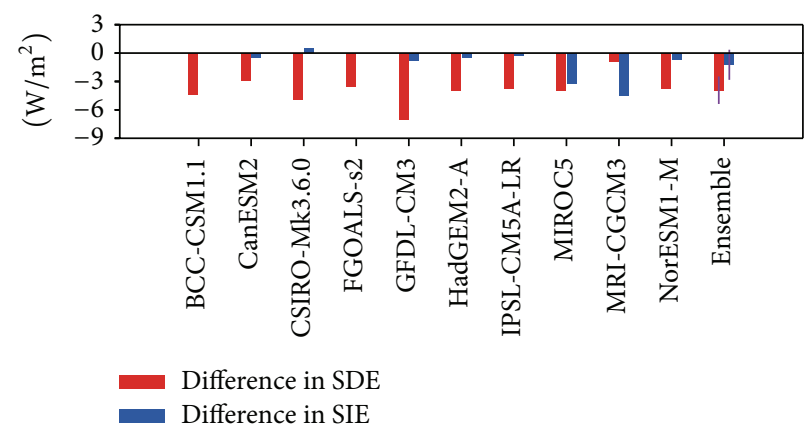

(c)

FIGURE 4: Difference between the aerosol run and CTL run in East China of (a) summer surface (a) temperature; (b) total radiation (black), shortwave radiation (red), and longwave radiation (blue) of aerosol forcing; and (c) direct (red) and indirect (blue) radiation of aerosol forcing. The far right bar and purple line in each panel are the ensemble mean and standard deviation from all simulations, respectively.

convergence, a weakening of water vapor flux, a stabilization of the atmosphere, and reduced precipitation. In summary, based on our analyses of the large-scale circulation regimes and moisture flux, we can conclude that inhomogeneous land-sea cooling reduces the meridional heating gradient, decreasing lower-tropospheric northward moisture transport and causing a reduction in precipitation over East China.

\subsection{Aerosol-Induced Radiative Forcing and Surface Temper-} ature Variations. Aerosols can perturb the energy balance of the earth by scattering and absorbing sunlight and by modifying clouds, hence inducing climate change [8]. In order to illustrate the linkage between anthropogenic aerosols and EASM precipitation, we calculate the regional average temperature and radiative forcing in East China.

In general, the surface temperature decreased in response to the aerosol effect in East China, except in the MRI-CGCM3 model. The decrease ranges from 0.1 to $0.3 \mathrm{~K}$, with the average cooling in the 10 models being about $0.15 \mathrm{~K}$ (Figure $4(\mathrm{a})$ ). A decrease in land surface temperature can abate the landsea thermal contrast on the one hand and may enhance the stability of the lower atmosphere and restrain air convection on the other hand, thereby suppressing rainfall [11].

The models produce a surface shortwave radiative forcing (RF) estimate from aerosol of $-4.2(-7.8$ to -3.0$) \mathrm{W} / \mathrm{m}^{2}$, while the longwave RF estimate from aerosol of $+0.5(+0.1$ to +1.2$) \mathrm{W} / \mathrm{m}^{2}$ partially offsets the changes in shortwave RF
(Figure 4(b)). The shortwave (longwave) radiation usually tends to cool (warm) the Earth's surface. It is noted that the shortwave radiation contributes to the total radiation more significantly than the longwave radiation, and the cooling effect on the surface temperature over East China is mainly because of shortwave radiation. For the total surface shortwave RF, one can further distinguish it into direct and indirect parts. Figure 4(c) indicates that the ensemble mean of surface direct (indirect) $\mathrm{RF}$ is about $-3.9 \mathrm{~W} / \mathrm{m}^{2}\left(-1.2 \mathrm{~W} / \mathrm{m}^{2}\right)$, varying from -7.2 to $-0.9 \mathrm{~W} / \mathrm{m}^{2}\left(-4.5\right.$ to $\left.0.5 \mathrm{~W} / \mathrm{m}^{2}\right)$, and most of the indirect RFs are negative except in the CSIRO-Mk3.6.0 model. The values of RF show large differences among all the models, and this can be attributed to the intricate aerosolcloud-radiation interactions.

In summary, direct and indirect RF impact the shortwave and longwave radiative effect together, leading to a cooling of East China, inducing a decrease of the land-sea thermal contrast, and thus weakening the EASM and reducing precipitation in East China.

\section{Conclusion and Discussion}

By analyzing simulations from 10 CMIP5 models, we found that the weakening effect of the EASM and the reduction in precipitation over East China with increased anthropogenic aerosols are robust. The combination of direct and indirect effects of anthropogenic aerosols can reduce 
surface total radiative forcing and cool continental East Asia. Subsequently, the decreased land-sea thermal contrast and SLP gradients can modulate the large-scale meridional circulation, decreasing moisture transport into East China and eventually suppressing precipitation in this region. There exists the weakening trend of the EASM and the decreasing of precipitation in East China since late 1970s [2, 22], and, at this period of time, aerosol concentrations began to increase rapidly in East Asia; hence, it is shown that the impact of anthropogenic aerosols may play a nonnegligible role in driving the weakened EASM [6]. Our results confirm that an increase in anthropogenic aerosols can lead to a weakening of the EASM and a decrease in precipitation in East China.

The weakening of the EASM's intensity and the concomitant reduction in precipitation are more significant in experiments that consider both the aerosol direct and indirect effects, rather than with the aerosol direct effect only. The ensemble mean of decreased precipitation in the aerosol run was circa $0.34 \mathrm{~mm} /$ day $(6.6 \%)$ in comparison to CTL run, and the reduction could be enlarged to $8.3 \%$ except in the experiments with the direct effect only. This may indicate an important role of the aerosol indirect effect in the EASM's circulation and local precipitation. Additionally, more than $80 \%$ of the decreased precipitation could be attributed to convective precipitation, which is consistent with the findings of Guo et al. [23].

However, we also found large discrepancies among the spatial distributions of aerosol-induced summer precipitation in the 10 models, despite the common feature that precipitation was reduced by anthropogenic aerosols over East China (Figure S2). It is possible that the uncertainties and discrepancies of the simulated precipitation are due to the complexity of aerosol-precipitation processes and model limitations in representing the features of precipitation in East China. There is great potential for improvement in the parameterizations of aerosol-cloud-precipitation interaction, as well as model skill in simulating the precipitation distribution over East China.

Finally, it is important to note that we focused on the fast component of anthropogenic aerosols in this study and did not pay attention to the slow response of SST change. Ganguly et al. [14] pointed out the importance of the slow response to aerosols for monsoon and precipitation. The slow response of the EASM and precipitation in East China to anthropogenic aerosols also needs to be fully explored with multimodel simulations in future.

\section{Conflict of Interests}

The authors declare that they have no conflict of interests regarding the publication of this paper.

\section{Acknowledgments}

This work was jointly supported by the National Basic Research Program of China (2011CB403406), the Chinese Academy of Sciences Strategic Priority Research Program (XDA05110101), and the National Natural Science Foundation of China (41105071 and 41290255).

\section{References}

[1] B. Wang, The Asian Monsoon, Springer Praxis Books, Praxis Publishing, Oxford, UK, 2006.

[2] C. Zhu, B. Wang, W. Qian, and B. Zhang, "Recent weakening of Northern East Asian summer monsoon: a possible response to global warming," Geophysical Research Letters, vol. 39, no. 9, Article ID L09701, 2012.

[3] D. Yihui and J. C. L. Chan, "The East Asian summer monsoon: an overview," Meteorology and Atmospheric Physics, vol. 89, no. 1-4, pp. 117-142, 2005.

[4] M. Xu, C.-P. Chang, C. Fu et al., "Steady decline of east Asian monsoon winds, 1969-2000: evidence from direct ground measurements of wind speed," Journal of Geophysical Research D: Atmospheres, vol. 111, no. 24, Article ID D24111, 2006.

[5] H. Li, A. Dai, T. Zhou, and J. Lu, "Responses of East Asian summer monsoon to historical SST and atmospheric forcing during 1950-2000," Climate Dynamics, vol. 34, no. 4, pp. 501$514,2010$.

[6] K.-M. Lau, S. C. Tsay, C. Hsu et al., "The joint Aerosol-Monsoon experiment: a new challenge for Monsoon climate research," Bulletin of the American Meteorological Society, vol. 89, no. 3, pp. 369-383, 2008.

[7] X. Zhang, "Aerosol over China and their climate effect," Advances in Earth Science, vol. 22, no. 1, pp. 12-16, 2007 (Chinese).

[8] IPCC, The Fifth Assessment Report of the Integovernmental Panel on Climate Change. WG1: Climate Change, The Physical Science Basis, Cambridge University Press, Cambridge, UK, 2013.

[9] Y. Zhang, "Online-coupled meteorology and chemistry models: history, current status, and outlook," Atmospheric Chemistry and Physics, vol. 8, no. 11, pp. 2895-2932, 2008.

[10] S.-P. Xie, B. Lu, and B. Xiang, "Similar spatial patterns of climate responses to aerosol and greenhouse gas changes," Nature Geoscience, vol. 6, no. 10, pp. 828-832, 2013.

[11] X. Liu, X. Xie, Z.-Y. Yin, C. Liu, and A. Gettelman, "A modeling study of the effects of aerosols on clouds and precipitation over East Asia," Theoretical and Applied Climatology, vol. 106, no. 3-4, pp. 343-354, 2011.

[12] Y. Jiang, X. Liu, X.-Q. Yang, and M. Wang, "A numerical study of the effect of different aerosol types on East Asian summer clouds and precipitation," Atmospheric Environment, vol. 70, pp. 51-63, 2013.

[13] F. Song, T. Zhou, and Y. Qian, "Responses of East Asian summer monsoon to natural and anthropogenic forcings in the 17 latest CMIP5 models," Geophysical Research Letters, vol. 41, no. 2, pp. 596-603, 2014.

[14] D. Ganguly, P. J. Rasch, H. Wang, and J.-H. Yoon, "Fast and slow responses of the South Asian monsoon system to anthropogenic aerosols," Geophysical Research Letters, vol. 39, no. 17, Article ID L18804, 2012.

[15] S. M. Uppala, P. W. Kållberg, A. J. Simmons et al., “The ERA40 re-analysis," Quarterly Journal of the Royal Meteorological Society, vol. 131, no. 612, pp. 2961-3012, 2005.

[16] B. Wang, Z. Wu, J. Li et al., "How to measure the strenght of the East Asian summer monsoon," Journal of Climate, vol. 21, no. 17, pp. 4449-4463, 2008.

[17] Q. Guo, "The summer monsoon intensity index in East Asia and its variation," Acta Geographica Sinica, vol. 38, no. 3, pp. 207-217, 1983 (Chinese). 
[18] J. Han and H. Wang, "Interdecadal variability of the East Asian summer monsoon in an AGCM," Advances in Atmospheric Sciences, vol. 24, no. 5, pp. 808-818, 2007.

[19] T. Zhou and L. Zou, "Understanding the predictability of East Asian summer monsoon from the reproduction of land-sea thermal contrast change in AMIP-type simulation," Journal of Climate, vol. 23, no. 22, pp. 6009-6026, 2010.

[20] D. Rosenfeld, U. Lohmann, G. B. Raga et al., "Flood or drought: how do aerosols affect precipitation?" Science, vol. 321, no. 5894, pp. 1309-1313, 2008.

[21] B. Wang and L. Ho, "Rainy season of the Asian-Pacific summer monsson," Journal of Climate, vol. 15, no. 4, pp. 386-398, 2002.

[22] H. Wang, "The weakening of the Asian monsoon circulation after the end of 1970's," Advances in Atmospheric Sciences, vol. 18, no. 3, pp. 376-385, 2001.

[23] L. Guo, E. J. Highwood, L. C. Shaffrey, and A. G. Turner, "The effect of regional changes in anthropogenic aerosols on rainfall of the East Asian Summer Monsoon," Atmospheric Chemistry and Physics, vol. 13, no. 3, pp. 1521-1534, 2013. 

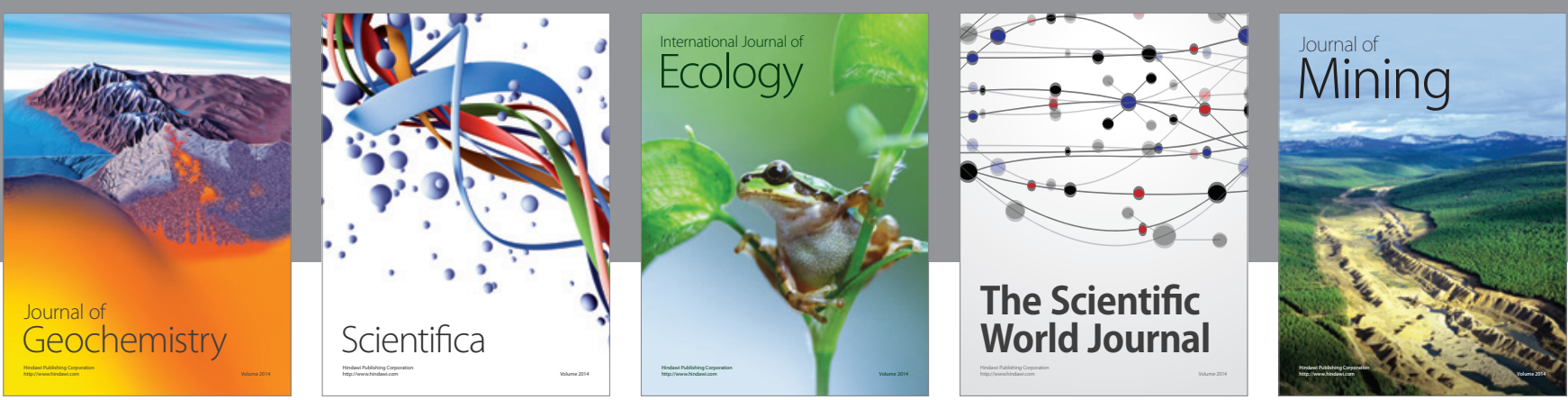

The Scientific World Journal
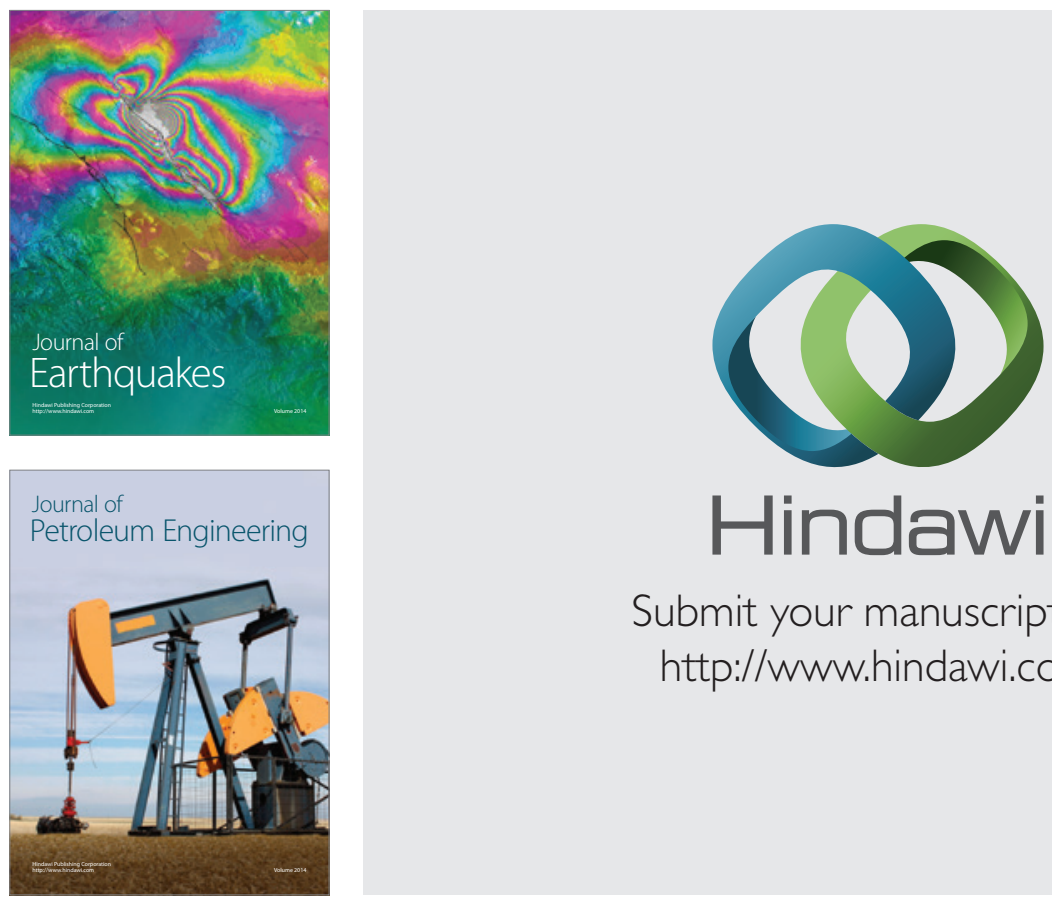

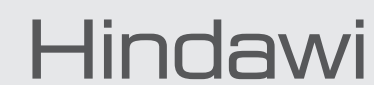

Submit your manuscripts at

http://www.hindawi.com
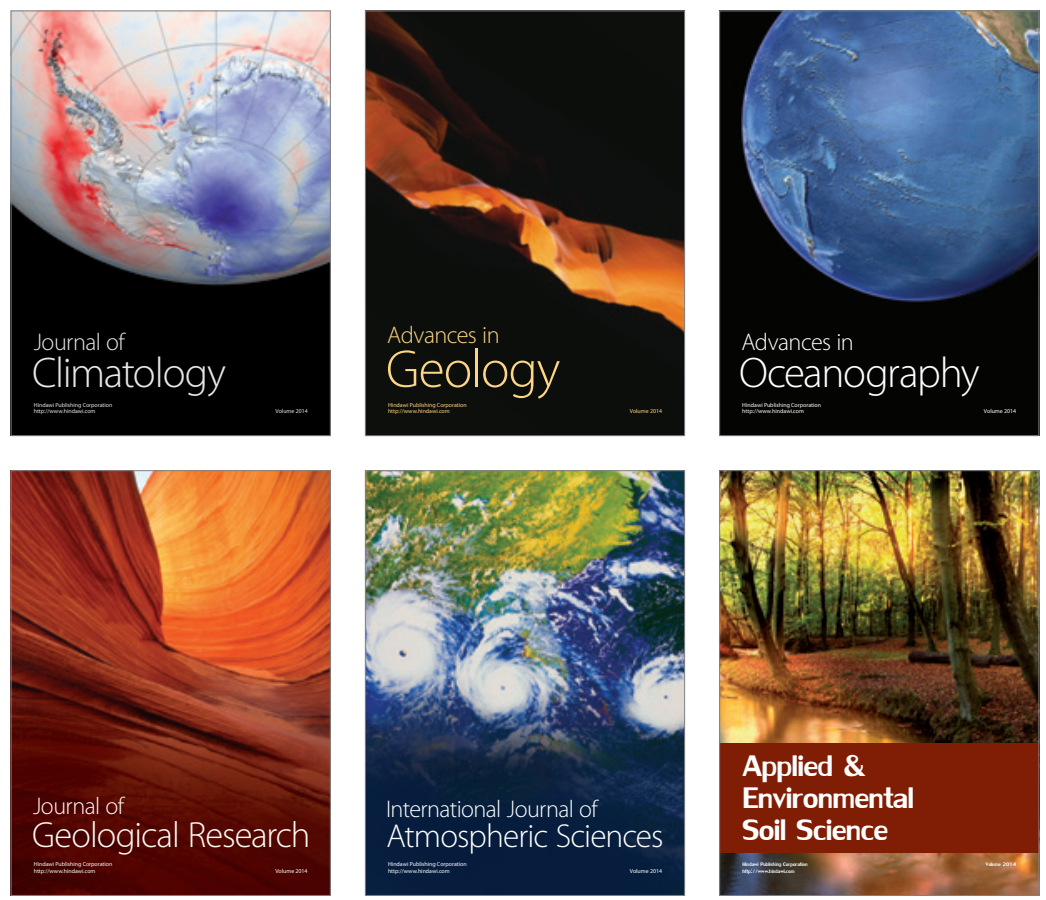
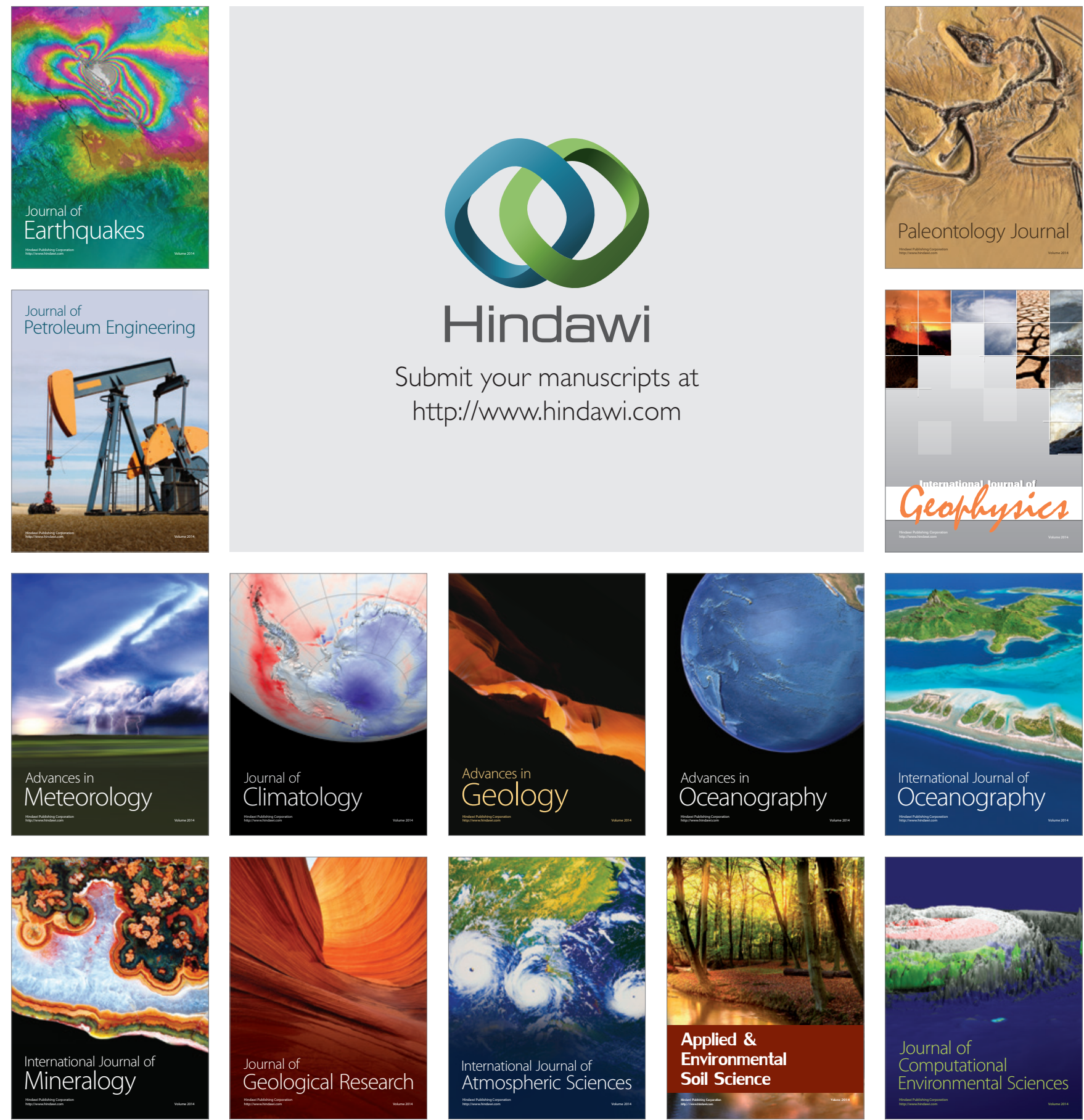